\title{
Brain activation via olfaction
}

\author{
Michael Leon \\ From 1st International Workshop on Odor Spaces \\ Hannover, Germany. 4-7 September 2013
}

Restriction of olfactory stimulation produces massive cell death in areas of the human brain not typically associated with olfactory perception: medial prefrontal cortex, cerebellum, insular cortex, orbitofrontal cortex, supramarginal gyrus, hippocampus, nucleus accumbens and the fusiform gyrus. These brain areas participate in: inference of the intentions of others, maintenance of attention, response to language, social judgment, production of language, formation of memories, motivation, and the recognition of human faces, all significant problems for individuals who have autism. Indeed, all of these same brain areas are adversely affected in the autistic brain. We therefore treated children who have autism using olfactory stimulation, potentiated by pairing it with tactile stimulation to activate these brain areas on a daily basis. Other sensory stimuli were also included in a brain activation program. In a randomized clinical trial, we used a standard test to confirm a 'full' autism diagnosis in all children and then gave an IQ test and a test of autism severity at baseline and at 6 months. We found that $42 \%$ of the brain activation group and $7 \%$ of the control group that received only standard-care treatments had a clinically significant improvement in their symptoms. Moreover, there was a 10.5-point difference in the IQ scores of children given brain activation therapy relative to control group scores. In addition to being much more effective than standard therapies, there was no need for expensive skilled therapists to produce these improvements. Finally, the average age of those treated in the study was well beyond the age at which standard therapies have been shown to have beneficial effects. Brain activation via olfactory stimulation may therefore be an effective low-cost therapy for a wide range of children with autism. As most children with autism have special sensitivities to odors, these brain areas may constitute a system that mediates those perceptual sensitivities.

Submit your next manuscript to BioMed Central and take full advantage of:

- Convenient online submission

- Thorough peer review

- No space constraints or color figure charges

- Immediate publication on acceptance

- Inclusion in PubMed, CAS, Scopus and Google Scholar

- Research which is freely available for redistribution 